\title{
Blinded to Their Own Daily Sufferings: the Lived Experience of Patients With Chronic Obstructive Pulmonary Disease in Ethiopia
}

\section{Mulugeta Tamire ( $\sim$ awonmuller@yahoo.com )}

Department of Preventive Medicine, School of Public Health, Addis Ababa University, Addis Ababa Aschalew Worku

Department of Internal Medicine, School of Medicine, Addis Ababa University

\section{Adamu Addissie}

Department of Preventive Medicine, School of Public Health, Addis Ababa University

\section{Samuel Ayele}

Splash International, Ethiopia

\section{Tewodros Haile}

Department of Internal Medicine, School of Medicine, Addis Ababa University

\section{Amsalu Bekele}

Department of Internal Medicine, School of Medicine, Addis Ababa University

\section{Research article}

Keywords: Chronic Obstructive Pulmonary Disease, lived experience, qualitative research, Ethiopia

Posted Date: November 17th, 2020

DOl: https://doi.org/10.21203/rs.3.rs-105773/v1

License: (9) (i) This work is licensed under a Creative Commons Attribution 4.0 International License. Read Full License 


\section{Abstract}

Background: Worldwide, chronic obstructive pulmonary disease (COPD) continues to be an important contributor to morbidity, mortality and health-care costs. In Ethiopia, the physical, financial, emotional, social and religious life of patients living with COPD is poorly understood, information crucial for physicians in developing treatment strategies and government agencies in planning community support services. This study, the first of its kind, was designed to initiate understanding of the personal burden of living with COPD in Ethiopia.

Methods: This was a qualitative research study using a phenomenographic approach. Twelve recruited COPD patients underwent in-depth interviews using a semi-structured open-ended interview guide. All audio-records were transcribed verbatim and translated to English for analysis using Atlas.ti software.

Results: There were seven men and five women, whose ages ranged from 45 to 78 years. One male participant was a former smoker and one female participant had second-hand cigarette exposure. All 12 participants were unaware of their COPD diagnosis despite experiencing chronic symptoms of cough and shortness of breath, unresponsive to treatment, which affected their physical, financial, emotional, social and religious life. In addition, all participants attempted a variety of coping strategies to deal with their respiratory disease and many were optimistic about their future living with the disease.

Conclusions: The findings of this study indicate an urgent need for improved awareness, diagnosis and treatment of COPD patients to lessen the burden of those living with the disease and more judiciously, utilize available resources in Ethiopia.

\section{Background}

Chronic obstructive pulmonary disease (COPD) is one of the leading worldwide causes of morbidity and mortality $(1,2)$. In the 2016 Global Burden of Disease report, the prevalence of COPD was estimated to be 251 million cases. In that same report, COPD was the seventh and tenth leading cause of disabilityadjusted life years (DALY) in high and low or middle-income countries (3). From 1990 to 2020, COPD rose from twelfth to fifth place on the World Health Organization global ranking of DALYs (4).

The 2019 Global Burden of Disease Study also reported a COPD mortality of 3.17 million deaths, accounting for $5 \%$ of all deaths that year. COPD is projected to be the fourth leading cause of global death by 2030 , more than $90 \%$ of these deaths occur in low and middle-income countries (5) and in 2016, COPD was ranked fourth among the top ten causes of mortality in Africa (2).

COPD morbidity and mortality in Sub-Saharan Africa, including Ethiopia, may be underestimated. Like other countries in Sub-Saharan Africa, most of Ethiopia is rural, where medical expertise is limited and public awareness of the disease greatly lacking (5). Although the percentage of the population smoking cigarettes, a known cause of COPD, remains low, exposure to household air pollution, is extensive in the region $(6,7)$. As a country, Ethiopia is dependent on biomass fuel, mainly wood and charcoal, for cooking 
and heating (8). A literature review of COPD prevalence from 1970 to 2001 reported 5.5\% prevalence of COPD in Ethiopia (9). Based solely on Ethiopia's rapidly expanding population (10), the occurrence of COPD and its disease burden may exceed currently predicted rates as studies have shown that COPD prevalence increases with age $(11,12)$.

Patients with COPD are known to have an impaired quality of life and poor emotional well-being $(13,14)$. Often overlooked is the stress on family and care-givers $(14,15)$. In Ethiopia, how COPD affects the physical, financial, emotional, social and religious life of patients living with the disease is poorly understood. This information is crucial for physicians in developing treatment strategies and government agencies in planning community support services and in turn, only through these efforts can the adverse and financial impact of COPD on existing health systems be addressed.

This study, the first of its kind, is designed to begin to understand the personal burden of living with COPD in Ethiopia.

\section{Methods}

\section{Study Setting}

Participants were recruited from the Chest Clinic of Tikur Anbessa Specialized Hospital (TASH) in Addis Ababa from January to February 2019. TASH is the largest public tertiary referral hospital in Ethiopia with a total bed capacity of approximately 700 . The Chest Clinic provides outpatient diagnostic and therapeutic services to patients with pulmonary problems including COPD. The Chest Clinic operates three times per week with an average of 60 patients per day.

\section{Study Design}

We applied a qualitative study design using a phenomenographic approach, which evaluates the variation of people's conceptions or perspectives of a given phenomenon in their surrounding world (16). The way people understand the phenomenon under consideration differs based on the attitudes, values, thoughts and opinions and information about people's conception gathered from their speech and actions (17). We chose this approach seeking to gain an in-depth understanding of the nature and meaning of COPD as lived and experienced by patients.

\section{Participants and Recruitment}

Based on the literature, 20 individuals are usually enough to discover all the different ways of understanding the phenomenon under consideration $(18,19)$. In this study, we originally recruited 39 COPD patients from another ongoing study, who were identified based on symptoms and spirometric results by trained nurses. The first and last authors, trained and certified in spirometry, reviewed the spirometric results to avoid misclassification. However, there were only fifteen who had correct addresses and were living in Addis Ababa; three were not willing to participant in the study due to personal reasons. 


\section{Data Collection}

In-depth interviews were conducted among COPD patients using a semi-structured open-ended interview guide at TASH in a noise-free separate room to maintain privacy. One interview was conducted at home and one was conducted on the phone. Two of the authors (MT and SA), one with rich experience of qualitative researches and the other with adequate experience in qualitative data collection, carried out the interviews. The interview guide was prepared in English and translated into Amharic language by an experienced translator with back-translation to check for consistency. The guide was reviewed before actual data collection to identify potential implementation difficulties with COPD patients. All interviews were tape-recorded using a digital recorder; field notes were also taken to capture information not available in the audio recordings. All interviews were carried out in Amharic except for one patient, who was not be able to speak or listen to the language requiring his son to serve as a translator during the interview.

\section{Data Analysis}

All audio-records (mean duration of 38 minutes) were transcribed verbatim and translated into English for analysis. All transcripts and translations were cross-checked with the audio files for accuracy and consistency. To identify and discern the participants' experiences into a limited number of categories, we employed Sjöström \& Dahlgren (2002) seven steps phenomenographic data analysis (20) explained as follows

\section{Familiarization step}

Reading and re-reading through the transcript to become familiar with the content while correcting any mistakes.

\section{Compilation step}

The meaning units were identified from each content area of the transcripts to deduce similarities and differences.

\section{Condensation step}

The content relevant to the research objective was extracted from every transcript as a free quotation in the Atlas.ti software. This step reduced the longer text identifying the core content of each transcript.

\section{Classification step}

Grouping similar responses given to a specific question from each transcript into a preliminary group.

\section{Comparison step}


Comparisons of the selected statements in each group were made to find the variation categories, checking for the accuracy of the representativeness of the experience of the participants.

\section{Labelling step}

Appropriate labelling given for each category to express the essence of understanding its content.

\section{Contrasting step}

In the final step, we discovered the outcome space by comparing and contrasting the categories obtained to find the unique characteristics of each category.

We used ATLAS.ti version 8.0 software (Scientific Software Development GmbH, Berlin, Germany) to code and analyze the transcripts. Final finding findings were described by using the main categories.

\section{Trustworthiness}

Different measures were in place to establish the rigor in the research and findings. In order to ensure credibility, an experienced qualitative researcher led the team and appropriate discussions and debriefings were undertaken on a daily basis and information was collected from different types of patients. To ensure the dependability of the findings, as two of the authors (M.T. and S.A) conducted all the interviews, appropriate and consistent data analysis was applied. To this end, the codes from both coders were checked for consistency and consensus was achieved.

\section{Results}

\section{Background characteristics}

Study participants included 12 participants ( 5 women and 7 men) with between 9 and 30 years of experience living with COPD. Their ages ranged from 45 to 78 years; all but two were younger than 60 years of age; six males and two females were married, three females were widowed and one male was separated. Occupationally, seven of the participants, two females and five males, were currently employed either in the government or private sectors, while the rest had no current employment (three were retired). Monthly income of the participants ranged from 1,000 to 25,000 Ethiopian birr (ETB) with the median income of 2,350 ETB. Only one man had a previous history of cigarette smoking and one woman had secondhand smoke exposure from her husband. However, all were exposed to household air pollution because of solid fuel use; one of the participants was still preparing food using solid fuel. All live in Addis Ababa except one woman from a rural setting.

\section{Main Categories}

The six main categories of the finding are presented in Fig. 1. Categories and sub-categories are each presented separately. 


\section{The Reality and Initial Thoughts}

This category describes the first action of the patients when they became aware of being affected by the disease. Different reactions were reported by all but one patient. Under this category there were four subcategories, namely perceived as asthmatics and not COPD patients, started follow-up, nothing-no surprise and suspected exposure.

\section{Perceived as asthmatics and not COPD patients}

Surprisingly, not one of participants knew they had COPD; they all believed they had asthma. They claimed they were not told about their COPD diagnosis regardless of whether they attended government or private clinics. Some were disappointed when they were excluded from a follow-up research project on asthma based on their spirometry test result. Others even insisted they still had asthma and not COPD as their personal physicians had told them so.

"I came to Tikur Anbesa Specialized hospital for breath test (Spirometry test) a year before with other asthma patients. Finally, the doctor told me that my disease is not Asthma and they excluded me... (Participant coughs). Sometimes I wonder whether my disease is Asthma or not as my problem is getting worse than the other patients." Male IDI: 5

\section{Started follow-up}

The immediate action for eight of the patients was visiting health facilities and starting follow-up when they were told they had the disease. However, all of them assumed they had asthma and some stated they were confused when there was no clinical improvement, especially as the other asthmatic patients in their area showed some improvement after getting the same treatment.

"At time goes on, I started follow-up at health facility. I didn't go to hospital; I went to health centre in my neighborhood. I got relief for a while but the symptoms return shortly." (Male IDI: 2).

There were three patients who first starting traditional medicine on their own or at the advice of family or community members before seeking treatment at a health facility. One of the patients explained his experience on taking traditional medicine as follows:

"At the beginning, I started to cough then I felt shortness of breath. Then people around me told me that I am becoming asthmatic. Then I started to take traditional medicine like honey and black cumin but that didn't work for me. I get relief for a while but the symptoms come back later on. Then I went to health facility and have been following up since then..."(Male IDI: 3 )

"Some advised me to take butter through my nose and I did that. I also took honey. Neither of them worked for me." (Male IDI: 4)

\section{Nothing- no surprise}


For two patients, knowing their diagnosis did not lead to seeking further care. It was after the disease progressed that they started to take measures, be it traditional or modern medicine. A male participant mentioned the situation as follows:

"I did nothing. I was living in the countryside. When I moved to Addis Ababa, I became healthy for the time being. However, it came back to me after some time." (Male IDI: 4)

\section{Suspected exposure}

Participants were asked about the possible causes of their respiratory problem. For some participants, it was related to their religion and they believed it was determined by a supernatural force. Others claimed the disease resulted from their previous occupational exposures, which included working in a car garage, beauty salon (including wig making), printing factory (chemicals) and fertilizer plant (chemicals and dust). Still others thought their lung disease was the result of exposure to moisture in their childhood mud house.

"I used to work in printing factory. ... I started to feel chest tightness. I requested for transfer but the organization were not positive. My bosses were not supportive. I was very sick and I lag behind all other employees on everything including promotion. The workplace was very bad. There were chemicals and dusts." (Male IDI 6)

"I used to work in garage. I was a guard there and I used to clean the garage and burn the waste. I am not sure but I have suspicion that the reason I develop this disease is that." (Male IDI 4)

\section{Disturbed By Symptoms}

All patients experienced a variety of distressing symptoms especially when they worsened. Many reported that symptoms of cough, shortness of breath, chest tightness and wheezing frequently affected their daily life activities, while others mentioned sputum, tearing eyes, abdominal pain, fever and sweating, loss of appetite, nasal congestion and runny nose as symptoms that interfered with their lives.

For all patients the most difficult symptoms they experienced were shortness of breath and a continuous cough. One of the participants explained her suffering from an inability to breathe properly as follows:

"The most difficult thing is the tightness and shortness of breath. You can't be able to move as you want. You cannot breathe. I was sick in the last two months. I thought I was going to die. I return to life with oxygen support and hydrocortisone injection. It is difficult disease. You can take painkiller for other kinds of pain, but this is emergency, you have to get oxygen and other drugs to feel better or to survive." (Female IDI: 5)

For two of the patients, their symptoms were stable for a time, whereas others experienced periodic worsening triggered by movement, exposure to environmental factors such as indoor and outdoor air pollution or other environmental conditions along the roadway they frequently walked. All participants, except for one, indicated their symptoms were worsening over time. 
"In the last two to three years, there is much cough and chest tightness. I just get tired. I think it is because I felt short of oxygen. My hand and leg become weak. I get very tired. I urge to sit immediately" (Male IDI:

7)

Another woman from a rural setting also added that she suffers a lot when she is cooking or the living house is smoky and she stopped fetching water.

"The problem (breathlessness) become very difficult to even seat at home while cooking. I already stopped fetching water from the spring and how can I act as a wife if I cannot do the home activity at all." (Female IDI: 3)

\section{Disease Progression}

Several participants mentioned they thought their lung disease was worsening over time. They indicated that exacerbations were more common in their daily life. One of the participants mentioned the problem was worsening and the disease affected his daily life:

"... These days if I get common cold (flu), which is common to have in our country, the tightness from the disease will be very tiresome. Now the disease is worsening than the past." (Male IDI: 4)

Many patients with regular medical follow-up did not think their prescribed treatment was beneficial. One of the patients said it did not help him in anyway:

"... I went to health facility and have been following up since then (first visit), but nothing works for me." (Male IDI: 5)

Under this category there were also three sub-categories, namely swinging between well and sick, response to location and seasonal changes and improved after medication.

\section{Swinging between well and sick}

All the participants experienced times of improvement and times of deterioration. They reported that sometimes they perceived they were free from the disease but then they would experience more severe duration and intensity of poor health. For some patients, the temporary improvement gave them false hope that they had fully recovered from their respiratory disease.

A woman who experienced a severe cough and tightness during her previous job and stopped that job believed she has recovered because she had got relief from the symptoms, reflected as follows:

"Yes, now I only have problem in my nose. My nose gets little congested during the night time because of the cold weather at winter season. Thanks to God I am very fine now." (Female IDI: 1)

\section{Response to location and seasonal changes:}


Patients reported they usually experienced improvement in the disease with changes in location or seasons. However, one of the participants explained that he developed his breathing difficulty when he moved to a different place for field work.

Taking salbutamol inhaler by discontinuing the interview, another patient also explained the relief he gets when he temporarily moves from Addis Ababa, where he permanently lives, to another location as follows:

"I feel sick when I live in Addis Ababa and I feel fine when I go somewhere else. Weather change could be another reason. I feel congested in Addis Ababa and I started to take salbutamol after the symptoms were worsened." (Male IDI: 5)

\section{Improved after medication:}

For some patients the short-lived symptomatic relief experienced after taking bronchodilator therapy led them to assume that over time they would no longer have the respiratory disease. One patient described this as a phenomenon that confused him as his relief was much more temporary compared with other asthmatic patients who were receiving the same bronchodilator medications. However, some of the patients felt dissatisfied with their current medication and treatment from their follow up visits and blamed their lack of improvement on inadequate medical attention.

"I am fine when I take the medication... The main problem is weakness. My leg and hand gets weak and I want to sit down" (Male IDI: 1)

\section{All-around Impact}

Under this category there were four sub-categories namely: health related, financial, psychological and emotional and social and cultural.

\section{Health-related}

All participants stated that daily suffering from shortness of breath and a cough totally compromised their health-related quality of life. They also indicated their normal sleep duration was interrupted due to their respiratory symptoms. A female patient explained the difficulty of living with the disease and suffering from lack of proper sleep during the night due to the cough and breathlessness as follows:

"... being unable to sleep, being unable to breathe as you desire. I'm sure every patient troubled with the feeling during the night. It is very difficult." (Female IDI: 1)

Others also stated they were unable to live a normal life due to disease-imposed restrictions on physical activity and movement. For those with a more severe disease, walking with others, especially when going uphill, is something they purposefully avoid. A woman patient stated her recent experience with walking as follows: 
"It is difficult. I can't walk with the same pace with another person. I tell people to go because I can't cope with their speed. I am fine if I go slowly. I told you that I can't try to go uphill especially in the last two years. I walk taking frequent breaks in between." (Female IDI: 2)

The limited physical activity and movement also affected many at work, making them less productive as stated below:

"I feel better when I take rest and it gets worse when I start to do work. When you get tightened, there will be a dry cough. Your head will be strained. It is a bad disease. I should take the inhaler immediately when I start to feel the symptom. But not all Ventolins reverse the symptom." (Male IDI: 6)

For another patient with high-level education and a managerial role, his lack of productivity affected the organizational output:

"I have a potential to do a lot in my workplace but I get tired because of the disease. I feel bad about it. If I were healthy, I could do my work exerting my best effort. I am a co-ordinator and I have a lot of activities to do. I spend shorter times in monitoring and I get back to office immediately when I get tired. If I were healthy, I would monitor the work for longer hours and return back to office at the end."(Male IDI: 4)

\section{Financial: direct and indirect costs}

The other impact of the disease, as explained by the participants, was the demand for the health care services and related cost of medications. Based on their living condition and income capacity, the patients complained they could not continuously afford the medications they depend on. Here the problem of cost is not only the direct cost for purchasing the medications including transportation or other health related expenditures, but also the indirect cost of limited work performance associated with loss of additional income and an inability of career advancement. A lack of improvement with the medications was also frustrating to the patients.

As the disease progressed, the demand for the health care increased as depicted by this 68-year-old patient:

"I go every month and at times when I get sick. In the past I used to go once in a month but nowadays I visit the health center at least twice a month." (Male IDI: 1)

Even those who had access to work provided health care found the cost of treatment exceeds their financial limit. Another group of participants left the public institution for timely and better care in the private sector.

The experience by the following patient explains the reality of such a situation:

"As I told you I moved to different places for work. Sometimes I pay for my treatment and the other times the government cover my cost. There are times that I pay and get treated at private facilities when the 
government clinics fail to give me adequate care. There are times that I spend big money that affects my family and myself. Anyways I get treated because I have to." (Male IDI: 3)

\section{Psychological and emotional}

In addition, disease impact is also manifest on the psychological and emotional well-being of the patients. Feeling hopeless, stressed in everyday situations and 'shunned by others as incapable' were common expressions.

A 65 year old patient, living with the disease for almost 25 years, perceived his disease as scary and his life with a constant fear of death:

"There are a lot of social events that you should participate but the disease won't allow you to be like others. I always carry my medication wherever I go. I try a lot not to get close to people. You feel ashamed. You may look fine now but you get tightened immediately in front of people. That is scary. You will feel sorry about yourself. It is psychologically touching. The disease is disgusting. It doesn't give you a chance to get calm in your life. I fear that I may die while asleep with shortness of breath." (Male IDI: 7)

\section{Social and religious}

Furthermore, people living with COPD also suffer from the impact of the disease on their social and religious life. Comments varied from not being able to attend social events because of physical tiredness and a continuous cough, which affected their comfort in front of others, to getting divorced and losing social value, the patients avoid social events or faith-based gatherings. At times, the patients felt the community members left them aside in group activities. Some even mentioned other community members being either worried during group-based social or religious activities assuming the disease could be transmissible or showed unwelcoming faces to keep them distant during events. Neighborhood rumors and spousal conception about contagion increased marital stress and at times led to ending of the union.

"At time when I got sick, I might not be able to perform my prayers as I wanted to. I just stand when it happened. I felt to miss something because I can't do what a normal person can. It was very difficult". (Male IDI: 2)

For another participant who already experienced a divorce because the disease, his intense coughing and breathlessness led to the dissolution of his second marriage as described below:

"I was married to another woman and we got divorced within a week of our marriage because she saw me having intensive cough. We got divorced because of it. This is social damage. She feared that I was going to die and she couldn't tolerate. She couldn't behave well and I left her to return back to family* despite the difficult situation. ... even I only have one child and I don't give birth to more children fearing that something may happen to me. (Male IDI: 4) (* specific area was mentioned by the respondent but we replaced it for privacy) 


\section{Coping Strategies}

The participants verbalized different coping strategies to overcome the symptoms of their respiratory disease and the related impacts. The attempts were different for each participant, based on their personal preferences and economic status. There were some who tried to alleviate the symptoms by doing physical exercise, getting massages, going to saunas or steam baths, while others also tried to avoid being exposed to what they expected as triggers. All of them visit health facilities seeking medications; some continued to use traditional ways of cures at their homes.

A 60 year old patient who lived for nine years with the disease described the benefit of massage:

"It (coping strategy) is hot massage. I lie in my back and there is a thing, which looks like a ball that roll over me. It radiates heat. I got massaged for three consecutive months. Then I became healthy for a while." (Male IDI: 3)

The last option for two of the respondents was changing their profession to better cope with the challenges and exacerbations of the disease. One claimed she continued to experience symptoms despite a change in career:

"It is now more than a year since I went there. Coincidentally I completely changed my profession and started my own business." (Female IDI: 5)

\section{Optimistic to the Future}

Despite ongoing symptoms and lack of improvement with medication, most patients remained optimistic they could lead a normal life. They expect the government will address their problem and the treatment will eventually cure them. One patient who suspected he may not have asthma adjusted his lifestyle thinking a cure would not occur.

Meanwhile, one patient faulted the government for not providing a cure and affordable medications to lessen his suffering as follows:

"Unless the government finds a cure, the only treatment option is to relief symptoms. If possible, it will be good if there is more efficient symptom reliever. The disease is very bad disease. It makes the patient suffers a lot.... It is agonizing since you can't take in or take out air easily. A lot of people died because of it. It is a killer. If a person can't take in air, it is bad." (Male IDI: 5)

\section{Discussion}

In this study, all 12 participants were unaware of their COPD diagnosis despite experiencing chronic symptoms of cough and shortness of breath which affected their physical, financial, emotional, social and religious life. This may reflect ineffective communication by health-care providers or 
misunderstandings on the part of the patients. Improving patient awareness of their COPD is crucial to lessen health-care over-utilization and financial strain on existing health systems.

Only two of the participants had exposure to tobacco smoke: one former smoker and the other because of environmental tobacco exposure. Given the low prevalence of tobacco smoking in the country, further research into other risk factors for COPD, including the use of biomass fuel, is indicated $(7,21)$.

Meanwhile, health promotion and protective measures in the community and in the workplaces should be initiated.

Study participants repeatedly mentioned that their lives were adversely affected by persistent and progressive respiratory symptoms. This was most profound during disease exacerbations. Similar to our findings, previous studies have also indicated that ongoing respiratory symptoms lessened the quality of life for those with COPD, varying by disease severity $(22,23)$. In addition, participants complained of the direct and indirect costs of medications, especially since symptoms did not improve with their use. With this knowledge, more individualized treatment plans by health-care providers may help reduce the persistence of COPD symptoms.

In our study, patients tried several coping strategies to improve their overall quality of life; some were more effective than others, many participants perceived increased walking and a temporary or permanent change in their place of residence or work environment could lessen their symptoms. However, all participants acknowledged their lung disease restricted their physical capabilities, causing anxiety, depression and a loss of religious activities $(24,25)$.

Our findings are in concert with several population-based studies also reporting that those with COPD had a reduced physical performance, more impaired disease-specific health status, and social deprivation compared with non-COPD participants $(26,27)$. Other researches have shown that daily stress aggravates depression and worsens the quality of life in those with $\operatorname{COPD}(28,29)$. Many patients found religious activities were a good way to cope with their disease; yet most were unable to participate. Pulmonary rehabilitation, currently not available in Ethiopia, may help reverse physical inadequacies and allow patients to return to important personal coping tactics (22).

Many participants were dissatisfied with their response to treatment and sought alternative therapies, possibly resulting in a more advanced stage of disease. A previous study of cancer patients and their families indicated that performing spiritual acts (using holy water) or seeking care from traditional healers recurred because of the hopelessness and patient uncertainty about the effectiveness of conventional medicine (30). Widely dispersed treatment guidelines by the Federal Ministry of Health may improve disease outcomes, slow disease progression and lessen patient dissatisfaction.

\section{Strengths And Limitations}

This is the first study in Ethiopia to explore the life experiences of COPD patients. Although the number of patients was small, a wide distribution of ages and gender ensured diversity. Generalization of study 
findings may be limited as participants were selected from the Chest Clinic at a large tertiary facility. Also, all participants thought they were being treated for asthma which may have skewed the results. We tried to address this by explaining to the patients at the start of the study that their lung function tests indicated COPD and not asthma as the underlying lung disease.

\section{Conclusions}

Considering the current and predicted burden of lung diseases and their significant impact on the lives of patients and the nation, the findings of this study indicate an urgent need for improved physician education, public awareness and governmental programmatic interventions, only then can COPD patients in Ethiopia be properly diagnosed, treated and live a more fulfilled existence.

\section{Abbreviations}

COPD: Chronic obstructive pulmonary disease

DALY=disability-adjusted life years

IDI= In-depth Interview

FGD: Focus Group Discussion

\section{Declarations}

\section{Ethical approval and consent to participate}

Ethical approval for the study was obtained from the College of Health Sciences of Addis Ababa University. All participants were asked to give written consent for participation and for audio recording before commencement but after explaining the objective and importance of the study. Confidentiality and anonymity were maintained throughout the study. In addition, codes were used during transcription and overall analysis to further protect the confidentiality of the participants. Appropriate advice was given to the patients on lifestyle modification needed while living with COPD after completing the interview.

\section{Consent for publication}

Not applicable

\section{Availability of data and materials}

The audios, transcripts and coded data are available from the corresponding author and can be presented upon reasonable request.

Competing interest 
The authors declare no conflict of interest.

\section{Funding}

Not applicable

Authors' contributions: All authors were involved in the conception, design of the study, interpretation, reviewing drafts and approval of the final manuscript. M.T. and S. A. carried out data collection and analysis. A. B and A. W. were involved in reviewing and determining categories of description. MT drafted the manuscript.

\section{Acknowledgments:}

We would like to thank the study participants for their time and co-operation. We would also thank the NIHR Global Health Research Unit on Lung Health and TB in Africa at LSTM - "IMPALA" for helping to make this work possible. In relation to IMPALA (grant number 16/136/35) specifically: IMPALA was commissioned by the National Institute of Health Research using Official Development Assistance (ODA) funding. The views expressed in this publication are those of the author(s) and not necessarily those of the NHS, the National Institute for Health Research or the Department of Health. We are especially grateful to Dr. Charles Sherman and Judy Price for their involvement in editing the manuscript.

\section{References}

1. Collaborators GBDCRD. Prevalence and attributable health burden of chronic respiratory diseases, 1990-2017: a systematic analysis for the Global Burden of Disease Study 2017. The Lancet Respiratory medicine. 2020;8(6):585-96.

2. World Health Organization. The top ten causes of death [updated 24 May 2018; cited 21 Nov 2018. Available from: http://www.who.int/en/news-room/fact-sheets/detail/the-top-10-causes-of-death.

3. World Health Organization. Chronic obstructive pulmonary disease (COPD); key facts. (cited on Sep 24 2020) available from: https://www.who.int/news-room/fact-sheets/detail/chronic-obstructivepulmonary-disease-(copd)

4. Murray CJL, Lopez AD Alternative projections of mortality and disability by cause 1990-2020: Global Burden of Disease Study. Lancet 349199714981504

5. van Gemert FA, Kirenga BJ, Gebremariam TH, Nyale G, de Jong C, van der Molen T. The complications of treating chronic obstructive pulmonary disease in low income countries of subSaharan Africa. Expert review of respiratory medicine. 2018;12(3):227-37.

6. Sana A, Somda SMA, Meda N, Bouland C. Chronic obstructive pulmonary disease associated with biomass fuel use in women: a systematic review and meta-analysis. BMJ Open Respiratory Research. 2018;5(1).

7. Gordon SB, Bruce NG, Grigg J, Hibberd PL, Kurmi OP, Lam K-bH, et al. Respiratory risks from household air pollution in low and middle income countries. The Lancet Respiratory medicine. 
2014;2(10):823-60.

8. International Energy Agency, World Energy Outlook 2016. Traditional use of biomass for cooking in Africa - 2014.

9. Misganaw A, Mariam DH, Ali A, Araya T. Epidemiology of major non-communicable diseases in Ethiopia: a systematic review. J Health Popul Nutr. 2014;32(1):1-13.

10. The World Bank. Population growth (annual \%) - Ethiopia. https://data.worldbank.org/indicator/SP.POP.GROW?locations=ET (Accessed on Sep 21, 2020).

11. Waatevik M, Skorge TD, Omenaas E, Bakke PS, Gulsvik A, Johannessen A. Increased prevalence of chronic obstructive pulmonary disease in a general population. Respiratory medicine. 2013;107(7):1037-45.

12. Antó JM, Vermeire P, Vestbo J, Sunyer J. Epidemiology of chronic obstructive pulmonary disease. European Respiratory Journal. 2001;17(5):982.

13. Weingaertner V, Scheve C, Gerdes V, Schwarz-Eywill M, Prenzel R, Bausewein C, et al. Breathlessness, functional status, distress, and palliative care needs over time in patients with advanced chronic obstructive pulmonary disease or lung cancer: a cohort study. Journal of pain and symptom management. 2014;48(4):569-81.e1.

14. Malik FA, Gysels M, Higginson IJ. Living with breathlessness: A survey of caregivers of breathless patients with lung cancer or heart failure. Palliative Medicine. 2013;27(7):647-56.

15. Hutchinson A, Barclay-Klingle N, Galvin K, Johnson MJ. Living with breathlessness: a systematic literature review and qualitative synthesis. European Respiratory Journal. 2018;51(2).

16. Marton F. Phenomenography - Describing conceptions of the world around us. Instructional Science. 1981;10(2):177-200.

17. Larsson J, Holmström I. Phenomenographic or phenomenological analysis: does it matter? Examples from a study on anaesthesiologists' work. International Journal of Qualitative Studies on Health and Well-being. 2007;2(1):55-64.

18. Holmstro"m I, Halford C, Rosenqvist, U. Swedish health care professionals' diverse understandings of diabetes care. . Patient Education and Counseling. 2003;51(1):53-8.

19. Lundborg CS, Wahlström R, Dall'Alba G. Ways of experiencing asthma management. Variations among general practitioners in Sweden. Scandinavian journal of primary health care. 1999;17(4):226-31.

20. Sjöström B, Dahlgren, L. O. Applying phenomenography in nursing research. . Journal of Advanced Nursing. 2002;40(3):339-45.

21. Tamire M, Addissie A, Kumie A, Husmark E, Skovbjerg S, Andersson R, et al. Respiratory Symptoms and Lung Function among Ethiopian Women in Relation to Household Fuel Use. International journal of environmental research and public health. 2019;17(1).

22. Brien SB, Lewith GT, Thomas M. Patient coping strategies in COPD across disease severity and quality of life: a qualitative study. NPJ primary care respiratory medicine. 2016;26:16051-. 
23. Pozzar M, Volpato E, Valota C, Pagnini F, Banfi PI. How people with chronic obstructive pulmonary disease perceive their illness: a qualitative study between mind and body. BMC Pulmonary Medicine. 2020;20(1):120.

24. Da Silva GP, Nascimento FA, Macêdo TP, Morano MT, Mesquita R, Pereira ED. Religious coping and religiosity in patients with COPD following pulmonary rehabilitation. Int $\mathrm{J}$ Chron Obstruct Pulmon Dis. 2018;13:175-81.

25. Gergianaki I, Kampouraki M, Williams S, Tsiligianni I. Assessing spirituality: is there a beneficial role in the management of COPD? NPJ primary care respiratory medicine. 2019;29(1):23-.

26. Franssen FME, Smid DE, Deeg DJH, Huisman M, Poppelaars J, Wouters EFM, et al. The physical, mental, and social impact of COPD in a population-based sample: results from the Longitudinal Aging Study Amsterdam. npj Primary Care Respiratory Medicine. 2018;28(1):30.

27. Ng T-P, Niti M, Fones C, Yap KB, Tan W-C. Co-morbid association of depression and COPD: A population-based study. Respiratory medicine. 2009;103(6):895-901.

28. Lu Y, Nyunt MSZ, Gwee X, Feng L, Feng L, Kua EH, et al. Life event stress and chronic obstructive pulmonary disease (COPD): associations with mental well-being and quality of life in a populationbased study. BMJ Open. 2012;2(6):e001674.

29. Pumar MI, Gray CR, Walsh JR, Yang IA, Rolls TA, Ward DL. Anxiety and depression-Important psychological comorbidities of COPD. J Thorac Dis. 2014;6(11):1615-31.

30. Gebremariam A, Addissie A, Worku A, Assefa M, Kantelhardt EJ, Jemal A. Perspectives of patients, family members, and health care providers on late diagnosis of breast cancer in Ethiopia: A qualitative study. PLOS ONE. 2019;14(8):e0220769.

\section{Figures}




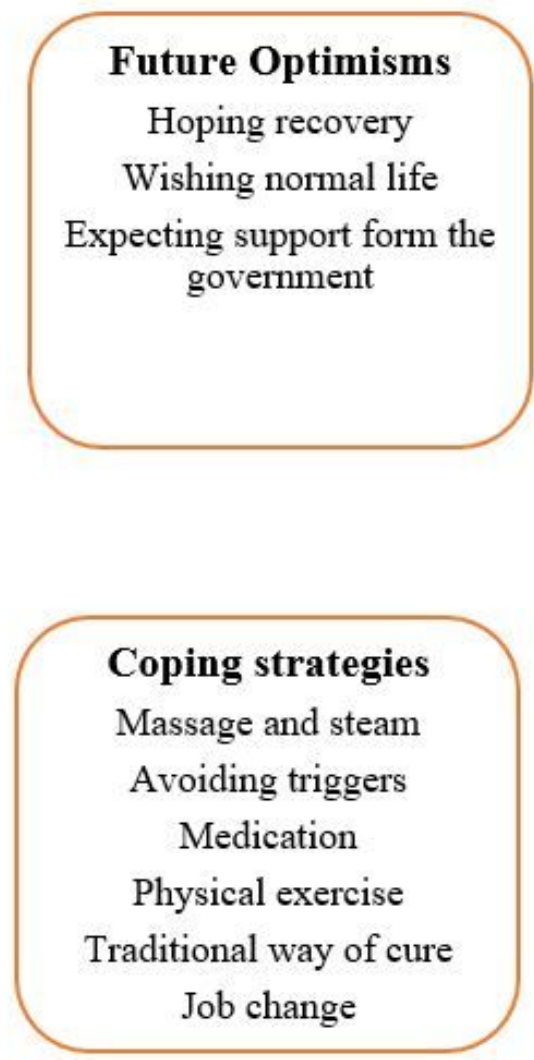

\section{The reality and intial thoughts}

Perceived as asthma

Did nothing/No surprise

Started follow-up

Did not know COPD

Suspected exposure

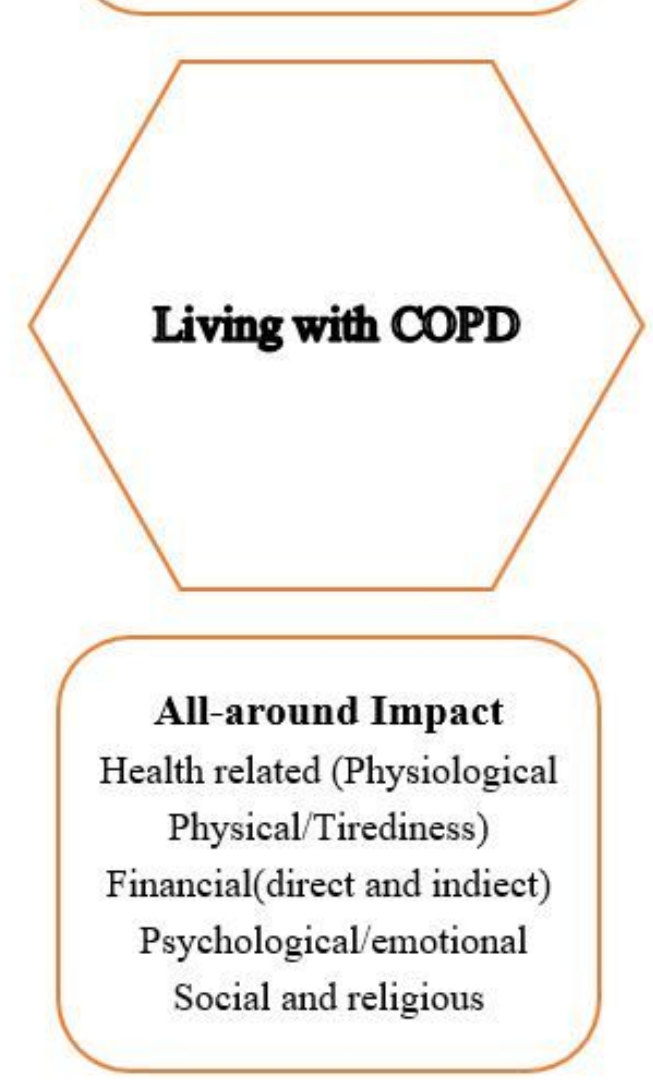

\section{Disturbed by symptoms}

Cough, abdominal pain, fever and sweating, loss of appetite, nasal congestion, runny nose, shortness of breath, sputum, tearing eyes, chest tightness, wheezing

\section{Disease progression:} Getting worse over time

No cure

Going and coming back

Response to changes: medication, location and seasonal

\section{Figure 1}

Diagrammatic representation of the main and sub-categories 

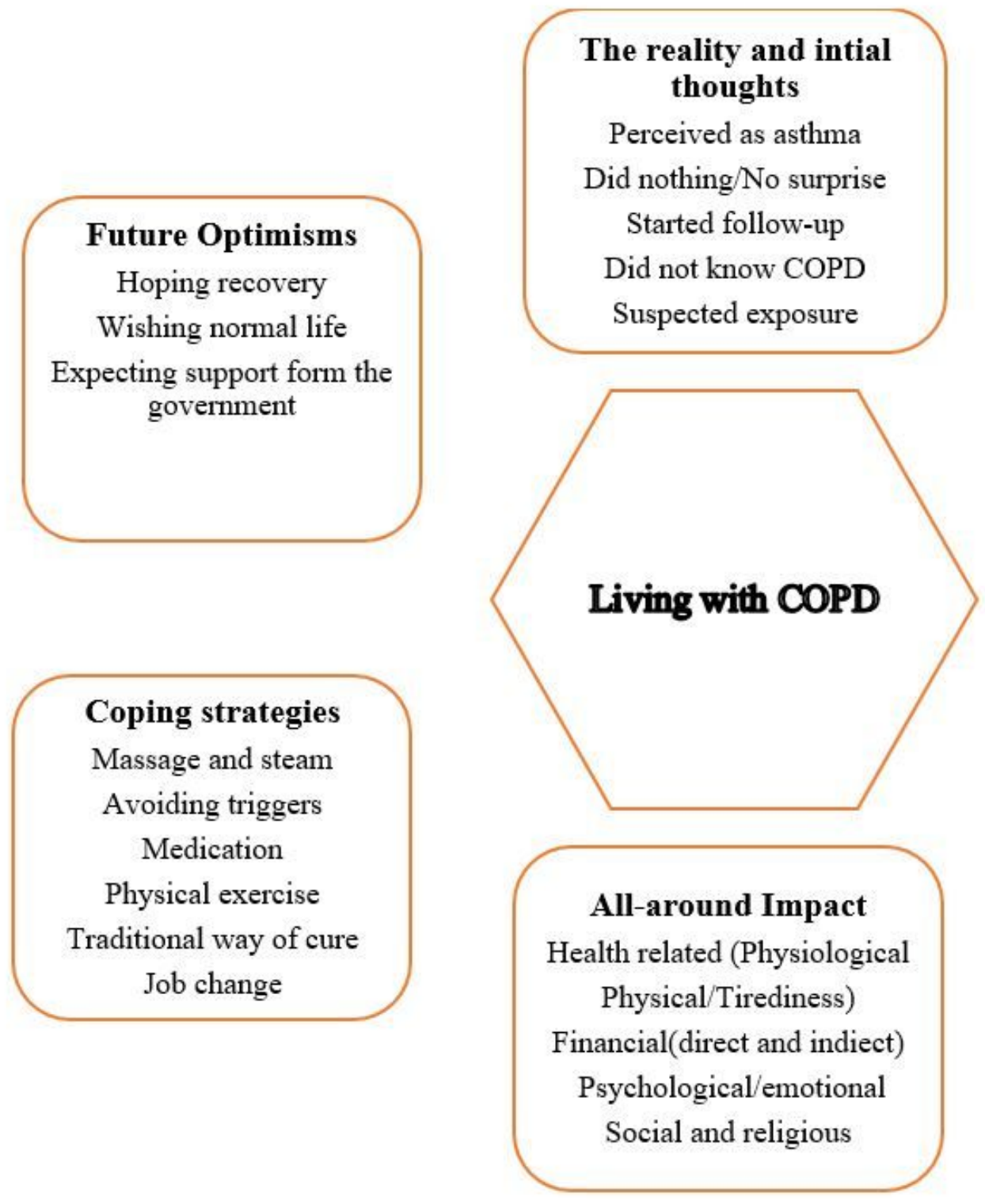

\section{Disturbed by symptoms \\ Cough, abdominal pain,} fever and sweating, loss of appetite, nasal congestion, runny nose, shortness of breath, sputum, tearing eyes, chest tightness, wheezing

\section{Disease progression: Getting worse over time}

No cure

Going and coming back

Response to changes: medication, location and seasonal

\section{Figure 1}

Diagrammatic representation of the main and sub-categories 